\title{
Challenges and management of neurological and psychiatric manifestations in SARS-CoV-2 (COVID-19) patients
}

\author{
Alessandro Orsini ${ }^{1} \cdot$ Martina Corsi $^{2}$ (D) Andrea Santangelo ${ }^{1} \cdot$ Antonella Riva $^{3} \cdot$ Diego Peroni $^{1} \cdot$ Thomas Foiadelli $^{4}$. \\ Salvatore Savasta ${ }^{4} \cdot$ Pasquale Striano $^{3,5}$
}

Received: 25 May 2020 / Accepted: 21 June 2020 / Published online: 6 August 2020

(C) Fondazione Società Italiana di Neurologia 2020

\begin{abstract}
COVID-19 is a pandemic caused by human coronavirus (HCoV) SARS-CoV-2, which originated in Wuhan, China, at the end of 2019 and spread globally during 2020. Due to the difficulty of clinical decision-making during this period, our study group reviewed current literature focusing on the neurological and psychiatric aspects of COVID-19. Despite the knowledge on this newly discovered virus which is constantly evolving, different pieces of evidence reported an association between COVID-19 and neurological symptoms like headache, dizziness, taste and smell disorders and complications involving the nervous system eventually triggered by the pathologic processes elicited by SARS-CoV-2. It seems that younger patients are less prone to develop severe forms of COVID-19. However, neurological signs have been reported in paediatric patients as well, and in some cases, the infection presented neurological sequelae. Furthermore, children with particular neurological diseases or treated with specific drugs (e.g. immune-suppressant therapies) must be carefully monitored during this pandemic. Neurologists should be aware of the main drug-drug interactions and the neurological side effects of COVID-19 treatments. Notably, adverse mental health impact has been reported in patients with SARS-CoV-2, which could be related either to the social strain or to the eventual neurotropic effects of the virus, which in other infections have been proven to promote the onset of psychiatric symptoms. Further, psychiatric population may be more vulnerable to the infection and at higher risk for adverse outcomes.
\end{abstract}

Keywords COVID-19 $\cdot$ SARS-CoV-2 $\cdot$ Coronavirus $\cdot$ Brain $\cdot$ CNS $\cdot$ Neurologic $\cdot$ Psychiatric

\section{Introduction}

In December 2019, several cases of unexplained pneumonia appeared in Wuhan, China. In January 2020, the cause

Martina Corsi

dott.martinacorsi@gmail.com

Alessandro Orsini

aorsini.md@gmail.com

Andrea Santangelo

androsantangelo@gmail.com

Antonella Riva

riva.anto94@gmail.com

Diego Peroni

perodiego@gmail.com

Thomas Foiadelli

thomas.foiadelli@gmail.com

Salvatore Savasta

s.savasta@smatteo.pv.it for such diseases was identified in a new enveloped RNA coronavirus detected in samples of bronchoalveolar lavage fluid from a Chinese patient [1]. Afterwards, further studies showed a close similarity with the virus responsible for

Pasquale Striano

strianop@gmail.com

1 Pediatric Clinic, Department of Clinical and Experimental Medicine, University of Pisa, Via Roma 67, 56100 Pisa, Italy

2 Psychiatric Clinic, Department of Clinical and Experimental Medicine, University of Pisa, Via Roma 67, 56100 Pisa, Italy

3 Pediatric Neurology Unit, IRCCS Istituto Giannina Gaslini, Genoa, Italy

4 Pediatric Clinic, Department of Pediatrics, Fondazione IRCCS Policlinico San Matteo, University of Pavia, Pavia, Italy

5 Department of Neurosciences, Rehabilitation, Ophthalmology, Genetics, Maternal and Child Health (DiNOGMI), University of Genoa, Genoa, Italy 
SARS infection in 2003; hence, it was named SARS-CoV-2 [2]. One month later, the illness associated with such virus was termed COVID-19. Due to the rapid and extensive spreading of the infection from China to Europe and worldwide, the WHO declared COVID-19 a public health emergency of international concern (PHEIC) [3], expressing the urge for a strong response from global public health. Up to date (June 7, 2020), more than 6.6 million confirmed cases of COVID-19 have been diagnosed worldwide, with 392.802 deaths [4].

Despite world updates produced daily, general knowledge of COVID-19 remains unclear. COVID-19 is mainly considered primarily a respiratory disease and so much of the guidance and papers focus on such physical manifestations and their management. Nevertheless, there is a possible viral transmission to the nervous system that may occur via circulation, an upper transcribrial or conjunctival route $[5,6]$. In the broad sweep of available data, neurological and psychiatric evidence on SARS-CoV-2 are limited. Reliable and up-to-date answers to immediate clinical questions can be difficult and time-consuming particularly regarding treatment strategies $[7,8]$.

We herein reviewed the best evidence on SARS-CoV-2 and neurological disorders simultaneously with COVID-19 neurological and psychiatric sequelae, including the paediatric population. Indeed, children affected by neurological disorders could be particularly vulnerable in the context of COVID-19, both directly because of their physical difficulties, but also because of the challenging issue of treatment needs alongside drug's long-term effects. These factors together with the adverse psychological effects of measures, such as self-isolation and disruption to normal healthcare and lifestyle, make this population worthy of attention [9, $10]$.

\section{Search strategy}

We performed a systematic search on PubMed using the terms "COVID 19" OR "coronavirus" AND "brain" OR "CNS" OR "neurologic "OR "psychiatric". We included case reports and clinical trials. Searches cover the period up to June 6, 2020. Only studies published in English were reviewed.

\section{CNS invasion by SARS-CoV-2}

Human coronaviruses ( $\mathrm{HCoVs}$ ) commonly share viral structures and infection mechanisms, together with the potential for host central nervous system (CNS) invasion $[11,12]$. The exact route by which $\mathrm{HCoVs}$ enter the CNS remains a topic of active investigation. Tissue distribution of host receptor angiotensin-converting enzyme 2 (ACE2) may not be solely sufficient to fully describe viral tropism $[11,13]$ and other mechanisms (such as axonal transport) are likely to be involved $[14,15]$.

Aerosol droplets allow $\mathrm{HCoVs}$ to firstly locate in the nasal mucosa of the infected host, subsequently gaining access to the CNS through a transcribrial route $[11,14,16]$. Concurrently, viremia disseminates $\mathrm{HCoV}$ through the bloodstream, which is an additional route to reach the cerebral blood flow [17]. Once in the CNS, the membrane-bound ACE2 receptor, which is ubiquitous and detectable also over the cerebral capillary endothelium, glial cells, and neurons, assures CoVs to fuse with cells' surface via spike proteins [17]. To prove this, mice transgenic ( $\mathrm{Tg}$ ) for human ACE2 resulted as highly susceptible to $\mathrm{CoV}$ inoculation, with broad brain invasion and death within a few days [15]. Once strong adhesion is guaranteed, an additional axonal transport leads to early infection spread to the piriform cortex and other regions associated with olfaction [14]. Within a few days after infection, $\mathrm{HCoVs}$ widely diffuse to the CNS, being detectable in the brains of infected mice or healthy patients time after the acute manifestations of the disease $[11,14]$. Similar mechanisms of neuronto-neuron $\mathrm{HCoV}$ transport might potentially involve all sensory nerves, depending on the entering site (e.g. nasopharyngeal or oropharyngeal). Therefore, the sensory branches of the trigeminal and vagal nerves may also lead to viral invasion of the brainstem nuclei, and later to the cerebrum and cerebellum $[11,14,16]$.

HCoVs share high similarities and common neurotropic features, and there is no evidence that SARS-CoV-2 may not be an exception [11, 18, 19]. First description of patients with meningitis or encephalitis whose cerebrospinal fluid (CSF) tested positive for SARS-CoV-2 by gene sequencing is described. Moreover, other neurological manifestations such as headache, impaired consciousness, psychiatric symptoms, and acute cerebrovascular diseases have been reported in patients with COVID-19 [12, 20-22]. The mechanism provided for cerebrovascular diseases, however, is probably different and does not require a direct viral invasion of the CNS. It seems that COVID-19 can cause a cytokine storm syndrome which, together with the elevation of D-dimer levels, platelet reduction, and hypoxia, may cause susceptibility to cerebrovascular events $[15,23,24]$. On the other hand, the systemic dysregulation of homeostasis in the infected host can influence the CNS, too. However, infected glial cells and neurons may also play a significant role in CNS tissue damage, having in vitro properties to secrete inflammatory cytokines and so potentially perpetuating inflammation and causing demyelination, oedema, and longterm neurological sequelae $[15,17,18,24]$. Moreover, the direct infection of cardiorespiratory centres in the CNS seems strong to contribute to respiratory failure and death in SARS-CoV-2-affected patients [11, 15, 18] (Fig. 1). 


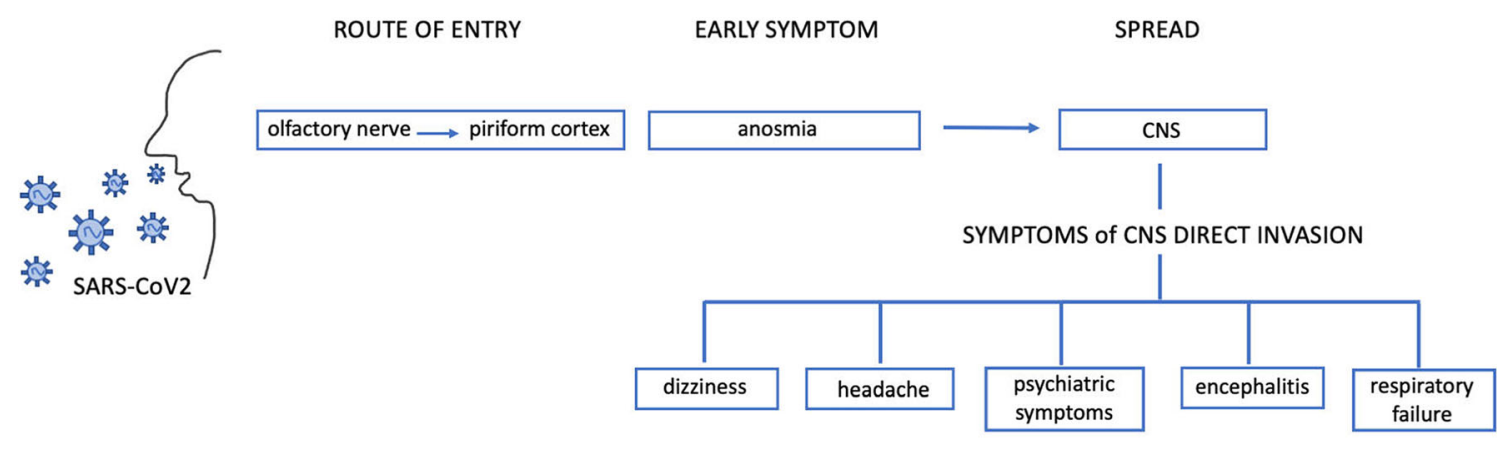

OTHER MECHANISMS of CNS DAMAGE
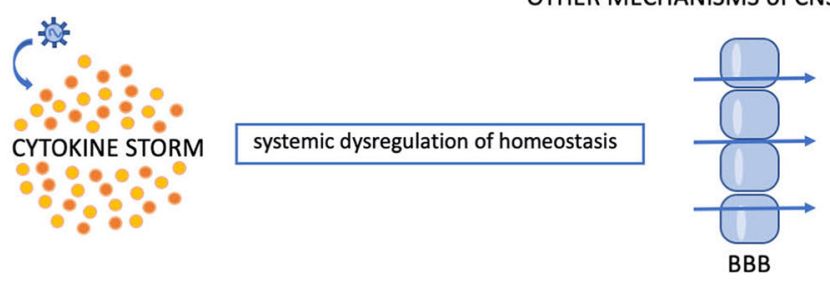

acute cerebrovascular diseases

acute haemorrhagic necrotizing encephalopathy

Fig. 1 Mechanisms of SARS-CoV-2 CNS invasion or damage and related symptoms. CNS = central nervous system; BBB = blood-brain barrier

\section{Neurological symptoms associated with SARS-CoV-2}

Similarly to other coronaviruses, SARS-CoV-2 could be associated with neurological complications. Such involvement has been observed in more severe cases and could be directly triggered by the virus itself or by the systemic consequences of the infection. Particularly, during elderly and in people with cardiac or endocrinological comorbidities, COVID-19 could manifest with fewer typical symptoms (namely flulike symptoms), giving otherwise rise to more severe neurological manifestations. Hence, COVID-19 has to be suspected in the differential diagnosis of patients with neurological symptoms, especially in highly epidemic environments [11, $22,25]$.

In the large study by Mao et al., 78 out of the 214 (36.4\%) patients did show neurological manifestations. Among these, the most common were dizziness and headache, whereas the peripheral nervous system (PNS) manifestations mainly included alterations in smell and taste (up to 5.6 and $5.1 \%$ of patients, respectively) [22]. Hitherto, the prevalence of COVID-19-related olfactory and taste disorders (OTDs) has been investigated through questionnaires and interviews [26, 27]. Results showed higher rates of OTDs in Europe compared with Asia and highlighted that olfactory disorders (both hyposmia and anosmia) are likely to appear even before other much-known symptoms of the COVID-19 [26]. Given that the olfactory and sensory nerves are supposed to be the first route to CNS invasion, and that it may precede the viral spread to other related cerebral regions [14], anosmia constitutes an interesting and early neurological manifestation of SARS$\mathrm{CoV}-2$ that may help for the timely suspicion and isolation of COVID-19 patients.
One of the first cases of COVID-19 with positive neurological signs was reported by Yin et al. [20], who described a patient with severe cognitive impairment, bilateral ankle clonus, positive Babinski, and meningeal signs. However, head CT scan was unremarkable and viral genome was not detected in the CSF. Nonetheless, similar findings have been reported as well in other patients $[28,29]$ whose cerebral spinal fluid tested positive for SARS-CoV-2 RNA, suggesting COVID19-related encephalitis. In one patient, brain MRI showed a signal hyperintensity in the medial temporal lobe on $\mathrm{T} 2$ and fluid-attenuated inversion recovery (FLAIR) sequences, consistent with the hypothesis of ongoing acute encephalitis. Furthermore, shreds of evidence have shown that SARSCoV-2 can elicit a cytokine storm, which in turn might be associated with severe organ damage, including the CNS. Poyiadji et al. [30] reported a patient with acute haemorrhagic necrotizing encephalopathy, a rare complication of specific viral infections [31] which has been linked to intracranial cytokine storms. In this patient, brain CT and MRI detected inflammatory lesions involving the medial temporal lobes along with the thalami and the insular regions. Moreover, we should consider that cytokine storms have been linked to the onset of multiple organ failure [32]; hence, they could also indirectly affect the nervous system.

Like other viruses and bacteria, it seems that SARS-CoV-2 as well could trigger acute cerebrovascular diseases (CVD), such as ischemic or haemorrhagic stroke and cerebral venous sinus thrombosis, which have been reported in several patients $[22,33,34]$. Stroke incidence was reported between 2.5 and $6 \%$ in retrospective European and Chinese studies [22, 35]. Such complications seem to be caused by alterations in the homeostasis of coagulation. It is noteworthy that patients with severe forms of COVID-19 showed higher levels of D-dimer 
[22] and more serious thrombocytopenia [36]. Nonetheless, numerous pieces of evidence have recognized the role of the inflammatory response as a contributor to the pathophysiology of cerebrovascular diseases [37]. Consistently with this evidence, higher concentrations of C-reactive protein have been reported in patients who developed CVD [33]. Recently, Li and colleagues [11, 19] further speculated that the involvement of the nervous system by SARS-CoV-2 may also play a role in the onset of respiratory failure occurring in COVID-19. ACE2 is expressed in the brainstem and the CNS replication of SARS-CoV-2 might directly involve the cardiorespiratory centre $[15,38]$. Additionally, the skeletal muscle injuries that have been documented in COVID-19 patients [22] might concur to the development of respiratory failure. Moreover, it is well known that severe hypoxia, which often presents in patients with COVID-19, can lead to brain damage with cerebral vasodilation and interstitial oedema. These effects might indeed be precipitated or worsened by an overlapping respiratory failure.

Finally, several authors reported cases of Guillain-Barré syndrome associated with SARS-CoV-2 infection [39-42]. The main etiopathological hypothesis involves "molecular mimicry", by which specific viral antigens and myelin or axonal epitopes may lead to cross-reactive of immune responses and inflammatory damage of the peripheral nerve fibres. Toscano and colleagues [40] described five patients who developed GBS 5-7 days after the onset of COVID-19 symptoms: Three of them presented an axonal variant, whereas two had a demyelinating form. Interestingly, CSF was negative for SARS-CoV-2 RNA in all cases, and anti-ganglioside antibodies were not detected in the three patients who were tested. A similar case was reported by Camdessanche et al. who described a 64-year-old man with a demyelinating form of GBS whose CSF is negative for anti-ganglioside antibodies [43].

\section{Impact of COVID-19 in patients with chronic neurological diseases}

SARS-CoV-2 infection has impacted on the health and wellbeing of patients with chronic neurological diseases. In fact, despite the lack of published evidence, it seems reasonable to presume that patients with chronic neurological disorders may both be at increased risk of contracting the virus (i.e. for primary or acquired immune deficiencies, higher risk of hospitalization and daily living in institutions) and of experiencing a more severe infection. Nonetheless, SARS-CoV-2, like other pathogens, may re-exacerbate or worsen previously diagnosed neurological diseases. For these reasons, many national and international scientific societies and disease foundations dealing with neurological disorders have acted to adequately inform, prevent and treat these patients [44]. Patients treated with biological drugs and immunosuppressive therapy (IST) are more vulnerable to all kinds of infections. Brownlee et al. [45] reviewed the indications for the management of patients with multiple sclerosis (MS) and neuromyelitis optica spectrum disorder (NMOSD) during COVID-19 pandemic. While enlightening the general lack of evidence about the risks of IST in milder forms of COVID-19, they recommended that clinicians should consider interrupting treatment in case of comorbidities or worsening of symptoms. However, there are contradictory opinions on this issue, since other authors suggest that the moderate immunosuppression induced by MS treatments may protect from developing more severe forms of COVID-19 [46]. In addition to this, authors expressed their doubts about the short-term usage of high-dose corticosteroids in MS relapses during the pandemic, since it does not influence the final degree of recovery and could be associated with a higher risk of viral reactivation [47]; therefore, they advised to keep a high threshold on the administration of such treatment. In patients requiring a high-efficiency therapy for MS during this period, natalizumab might be a better choice compared with other treatments that could lead to complications, such as transient lymphopenia, or increase hospital accesses for monitoring drug levels. No special advice so far has concerned children with MS [44].

Patients affected by neuromuscular diseases (NMD) should also be considered a population at more prone to COVID-19 complications [48]. Some of them may be at higher risk for infection, such as those with the involvement of swallowing and breathing muscles, with other comorbidities or under IST (such as steroids). Furthermore, infections can be a trigger for disease exacerbation or progression in NMD, like in myasthenia gravis [49] or spinal muscular atrophy, and patients with NMD and acute respiratory illnesses present a much higher risk of respiratory failure and need for intensive care. Hence, clinicians should consider that COVID-19 might not represent an exception to this evidence, and therefore worsen clinical conditions of patients with NMD or unmask previously undiagnosed pathologies. There are no current indications for interrupting or changing an ongoing therapy, even with immunosuppressant drugs [48]; however, careful surveillance of these patients should be advisable. Finally, a global pandemic is certainly a stressful event that can affect both physical and mental health, quality of sleep and daily routines. In this sense, patients with migraine or other headache disorders may be more prone to be affected by those stressors and experience more severe or more frequent headache episodes.

So far, most drugs used in paediatric patients seem to have no contraindications in COVID-19 [50]. Some initial doubts regarding the safety of NSAIDs (e.g. ibuprofen) have been rejected by the WHO and EMA [51] due to the lack of evidence on the association of their administration with a worse outcome of COVID-19. Nonetheless, recommendations may eventually change according to our better understanding of the 
disease. Evidence on these and other categories of patients are still to be obtained. Hence, a constant update of clinicians is required. Finally, due to the need of carefully monitoring their patients, child neurology specialists should consider that a helpful tool might be represented by telemedicine, which has been proven to obtain similar satisfaction rates and eventual outcomes compared with traditional visit for different diseases [52-54].

\section{Neurological complications of COVID-19-related treatments}

As treatment for COVID-19 constantly evolves, following the newest evidence of efficacy and clinical trials, neurologists should be aware and constantly updated on the main nervous system side effects of these therapies. Besides supportive treatments, the drugs that are mainly used both for children and adults are anti-inflammatory and antiviral agents, eventually in association with anti-thrombotic therapy [55].

The main interactions between antiviral therapies and neurologic and psychiatric drugs are reported in Table 1. Among these, chloroquine and hydroxychloroquine have been administered in COVID-19 even in milder forms [56, 57], although the use of both drugs has recently shown contradictory results [58-60]. In particular, a small Chinese randomized trial reported no differences in virologic outcomes [59], and the Survival Sepsis Campaign guidelines on the management of critically ill adults with COVID-19 stated that there was insufficient evidence for recommending the use of hydroxychloroquine and chloroquine in this group of patients. Different organizations, including the Italian Medicines Agency (AIFA), have suspended the employment of hydroxychloroquine outside clinical trials [61]. Seizures have been observed in the past in some patients treated with chloroquine [62]. Moreover, due to their association with QT prolongation, co-administration with drugs eliciting the same side effect (e.g. tricyclic antidepressants) is discouraged and should be carefully used in patients with cardiac diseases (e.g. NMDrelated heart failure). Furthermore according to Russo et al., chloroquine and hydroxychloroquine, as well as Remdesivir, an antiviral agent used in COVID-19 [63, 64], should not be co-administered with carbamazepine, phenytoin, phenobarbital and primidone, for the risk of drug interactions and enzymatic induction of inhibition [65]. Lopinavir and ritonavir have been employed in COVID-19 treatment [66], although contradictory results have been observed and their effectiveness is still debatable [67]. Moreover, ritonavir may promote the metabolism of phenytoin and other antiepileptic and antipsychotic drugs due to the induction of CYP450 [68]. Furthermore, azithromycin has proven efficacy in COVID19 in association with hydroxychloroquine [57]. Nonetheless, patients with myasthenia gravis taking macrolides should be monitored, as they have been reported to exacerbate symptoms or trigger a new-onset myasthenic syndrome [69]. Finally, the monoclonal antibodies employed in COVID-19 trials (mainly tocilizumab [66] and anakinra [70]) have not shown nervous system side effects or interactions with neurological diseases.

\section{Neurological involvement in children}

COVID-19 seems to have a relatively low prevalence in children, which represent from 1.7 [71] to $2.4 \%$ [72] of patients. In Italy, $1.9 \%$ of reported cases were $<19$ years old [73]. Nonetheless, SARS-CoV-2 infection shows different characteristics in children compared with the adult population, such as a longer incubation period (6.5 vs. 5.4 days [74]), a milder course and a reduced fatality [5]. Furthermore, typical symptoms of COVID-19 like fever, cough and shortness of breath have been reported less frequently in children $[5,10]$. Focusing on the neurological features, headache has been reported in up to $28 \%$ of the cases [71], being the principal neurological symptom, followed by confusion, in this age group [75].

Data on laboratory findings have been only occasionally described. However, Henry et al. [76] collected the findings from 12 studies reporting on 66 children. According to the authors, leukocytes were normal in the vast majority of patients $(69.2 \%)$, whereas factors related to abnormal coagulation, such as thrombocytopenia and increased D-dimer, are anecdotal. Moreover, C-reactive protein and procalcitonin were increased by $13.6 \%$ and $10.6 \%$ of the cases. Accordingly, it is reasonable to suspect that children have a lower risk of presenting SARS-CoV-2 neurological complications compared with adults.

Despite the milder expression of COVID-19 in the paediatric population, severe forms of the disease seem to occur mainly in younger children, with a prevalence of $10.6 \%$ and $7.3 \%$ for the age groups of $<1$ and $1-$ 5 years, compared with $4.2 \%, 4.1 \%$ and $3.0 \%$ for the age groups of 6-10, 11-15 and $>15$ years [5]. Although neurological complications in COVID-19 paediatric patients are a seldom finding, probably because of the milder forms of the disease, some cases have been reported. Sun et al. described a 10-month-old child who presented intussusception, multi-organ dysfunction syndrome, toxic encephalopathy, status epilepticus and disseminated intravascular coagulation [77]. Furthermore, seizures have been described in a 2-year-old girl in China, who did not develop other complications and was discharged after 2 weeks of hospitalization [78]. Finally, one case of encephalitis has been reported in a paediatric patient from Germany [79]. 
Table 1 SARS-CoV-2 drugs interactions with co-medications

\begin{tabular}{|c|c|c|c|c|c|c|c|c|c|}
\hline & $\mathrm{DRV} / \mathrm{c}$ & $\mathrm{LPV} / \mathrm{r}$ & RDV & FAVI & CLQ & HCLQ & NITA & RBV & OSV \\
\hline \multicolumn{10}{|c|}{ mood-stabilizing drugs } \\
\hline Lamotrigine & ^ LTG & $\downarrow$ LTG & $>$ & $>$ & $>$ & $>$ & $>$ & $>$ & $>$ \\
\hline Carbamazepine & $\begin{array}{l}\star_{\mathrm{CBZ}} \\
\downarrow \mathrm{DRV} / \mathrm{c}\end{array}$ & $\begin{array}{l}\uparrow \mathrm{CBZ} \\
\downarrow \mathrm{LPV} / \mathrm{r}\end{array}$ & $\downarrow \mathrm{RDV}$ & $>$ & $\nabla$ CLQ & $\downarrow$ HCLQ & $>$ & $>$ & $>$ \\
\hline Gabapentin & $>$ & $>$ & $>$ & $>$ & $>$ & $>$ & $>$ & $>$ & $>$ \\
\hline Valproic acid & $\downarrow \mathrm{DRV} / \mathrm{c}$ & $\begin{array}{l}\downarrow \mathrm{VPA} \\
\quad \text { (mild) } \\
\text { 个 LPV/r }\end{array}$ & $>$ & $>$ & $>$ & $>$ & $>$ & $>$ & $>$ \\
\hline Lithium & $>$ & $\uparrow \mathrm{QTc}$ & $>$ & $>$ & †QTc & A QTc & $>$ & $>$ & NA \\
\hline Pregabalin & 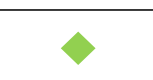 & $>$ & $>$ & $>$ & $>$ & $>$ & $>$ & $>$ & $>$ \\
\hline \multicolumn{10}{|l|}{ BDZs } \\
\hline Lorazepam & 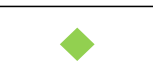 & $>$ & $>$ & $>$ & $>$ & $>$ & 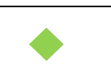 & $>$ & $>$ \\
\hline Diazepam & ^ DZP & $\uparrow^{\mathrm{DZP}}$ & $>$ & $>$ & $>$ & $>$ & $>$ & $>$ & $>$ \\
\hline Clonazepam & $\uparrow_{\mathrm{CZP}}$ & $\uparrow \mathrm{CZP}$ & $\nabla$ & 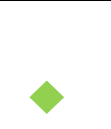 & 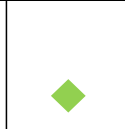 & 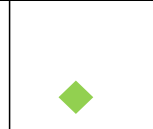 & 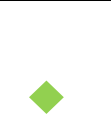 & 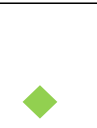 & 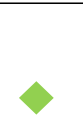 \\
\hline
\end{tabular}


Table 1 (continued)

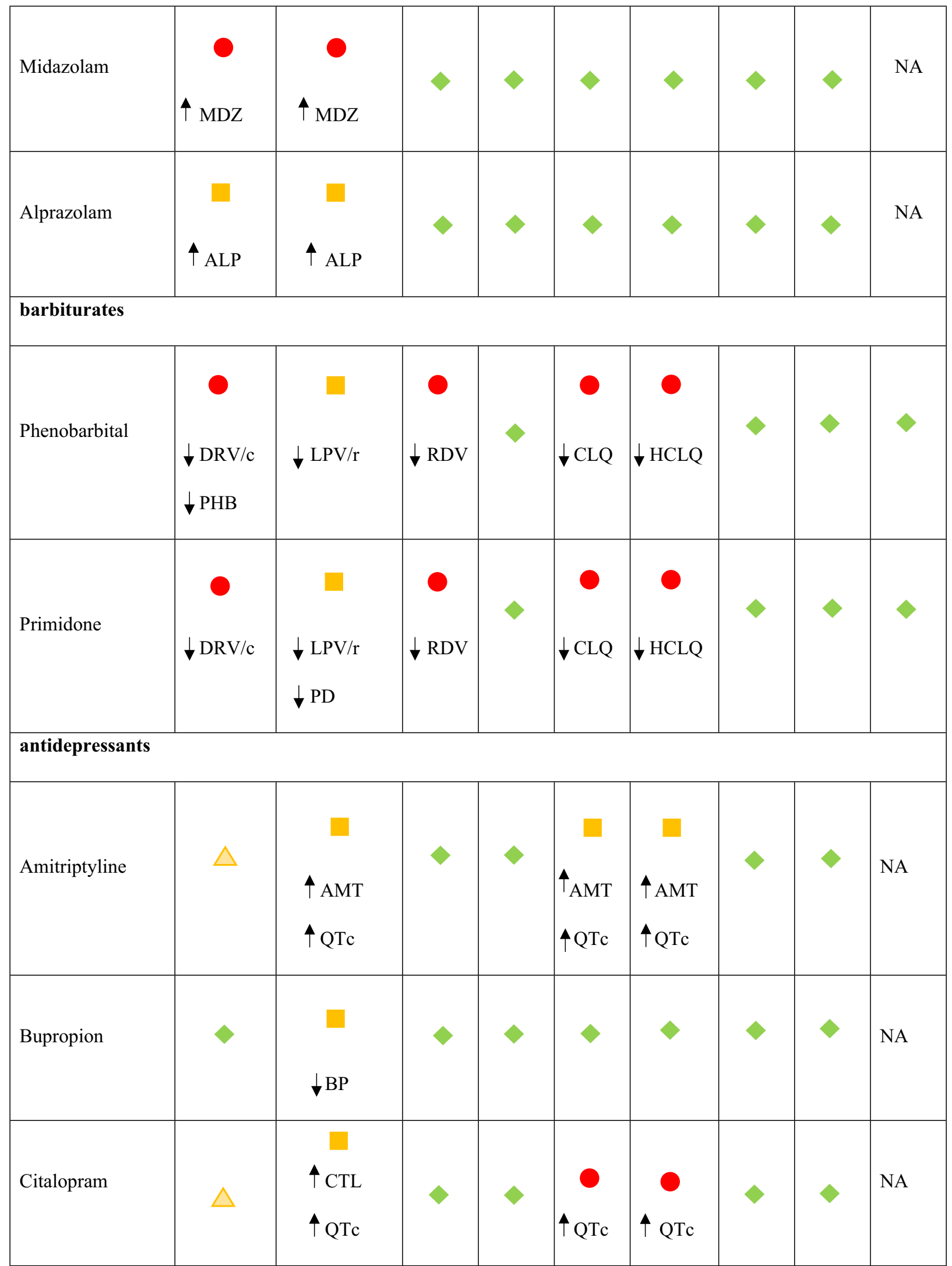


Table 1 (continued)

\begin{tabular}{|c|c|c|c|c|c|c|c|c|c|}
\hline Clomipramine & $\begin{array}{l}\uparrow_{\mathrm{CLP}} \\
\uparrow \mathrm{QTc}\end{array}$ & $\begin{array}{l} \\
\uparrow \mathrm{CLP} \\
\uparrow \mathrm{QTc}\end{array}$ & $>$ & $>$ & $\begin{array}{c}0 \\
\uparrow \mathrm{CLP} \\
\uparrow_{\mathrm{QTC}}\end{array}$ & $\begin{array}{c}\uparrow_{\mathrm{CLP}} \\
\uparrow_{\mathrm{QTC}}\end{array}$ & $>$ & $>$ & NA \\
\hline Duloxetine & $\triangle$ & $\triangle$ & $>$ & $>$ & $>$ & $\diamond$ & $>$ & $>$ & NA \\
\hline Escitalopram & $\triangle$ & $\begin{array}{l}\uparrow \mathrm{ESC} \\
\uparrow \mathrm{QTc}\end{array}$ & $\gamma$ & $\nabla$ & $\uparrow \mathrm{QTc}$ & ^ QTc & $>$ & $>$ & NA \\
\hline Mirtazapine & $\begin{array}{l}\uparrow \mathrm{MRT} \\
\uparrow \mathrm{QTc}\end{array}$ & $\begin{array}{l}\star_{\mathrm{MRT}} \\
\boldsymbol{\star}_{\mathrm{QTc}}\end{array}$ & $>$ & $>$ & $>$ & $>$ & 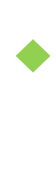 & $>$ & NA \\
\hline Paroxetine & $\downarrow \mathrm{PRX}$ & $\begin{array}{l}\text { ^ } \mathrm{PRX} \\
\uparrow_{\mathrm{QT}}\end{array}$ & $\gamma$ & $\gamma$ & $>$ & $>$ & 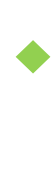 & $>$ & NA \\
\hline Sertraline & $\triangle$ & $\uparrow \mathrm{SRT}$ & $>$ & 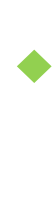 & $>$ & $\nu$ & $>$ & $>$ & NA \\
\hline Trazodone & $\boldsymbol{\uparrow}_{\mathrm{TRZ}}$ & $\begin{array}{l}\uparrow_{\mathrm{TRZ}} \\
\uparrow_{\mathrm{QT}}\end{array}$ & 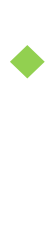 & $>$ & 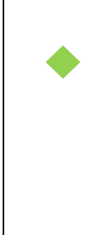 & $>$ & $>$ & $>$ & NA \\
\hline
\end{tabular}


Table 1 (continued)

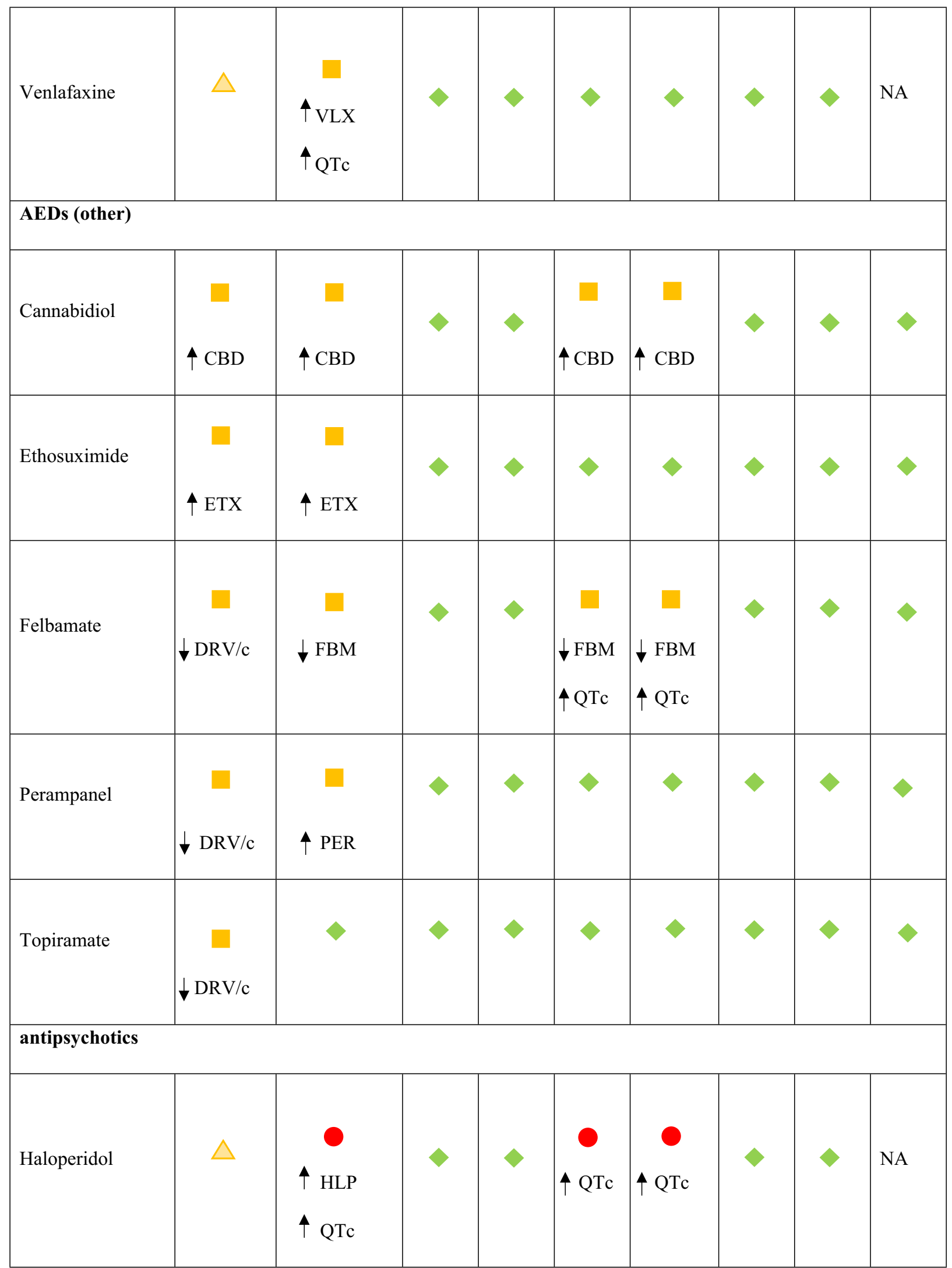


Table 1 (continued)

\begin{tabular}{|c|c|c|c|c|c|c|c|c|c|}
\hline Chlorpromazine & $\triangle$ & $\star_{\mathrm{CPZ}}$ & $>$ & $>$ & 个 CPZ & $\begin{array}{l}\uparrow \mathrm{CPZ} \\
\uparrow \mathrm{QTc}\end{array}$ & $>$ & $>$ & NA \\
\hline Risperidone & 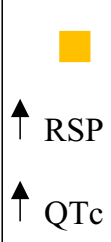 & $\begin{array}{l}\uparrow \mathrm{RSP} \\
\uparrow \mathrm{QTc}\end{array}$ & $>$ & $>$ & $\mid \begin{array}{l} \\
\uparrow_{\mathrm{RSP}} \\
\mathrm{T}_{\mathrm{QTc}}\end{array}$ & $\begin{array}{c}\uparrow_{\mathrm{RSP}} \\
\uparrow_{\mathrm{QTc}}\end{array}$ & 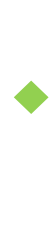 & 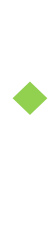 & NA \\
\hline Olanzapine & $>$ & $\downarrow$ OLP & $>$ & $>$ & (mild) & (mild) & $>$ & 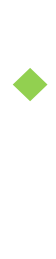 & NA \\
\hline
\end{tabular}

$D R V / c$ darunavir/cobicistat; $L P V / r$ lopinavir/ritonavir; $R D V$ remdesivir; FAVI favipiravir; $C L Q$ chloroquine; HCLQ hydroxychloroquine; NITA nitazoxanide; $R B V$ ribavirin; $O S V$ oseltamivir; $L T G$ lamotrigine; $C B Z$ carbamazepine; $V P A$ valproic acid; $O T c$ corrected QT interval; $N A$ not available, very low evidences; $B D Z$ s benzodiazepines; $D Z P$ diazepam; $C Z P$ clonazepam; $M D Z$ midazolam; $A L P$ alprazolam; $P H B$ phenobarbital; $P D$ primidone; $A M T$ amitriptyline; $B P$ bupropion; $C T L$ citalopram; $C L P$ clomipramine; $E S C$ escitalopram; $M R T$ mirtazapine; $P R X$ paroxetine; SRT sertraline; TRZ trazodone; $V L X$ venlafaxine; $A E D$ s anti-epileptic drugs; $C B D$ cannabidiol; $E T X$ ethosuximide; $F B M$ felbamate; $P E R$ perampanel; $H L P$ haloperidol; $C P Z$ chlorpromazine; $R S P$ risperidone; $O L P$ olanzapine

\section{Psychological burden and associated psychiatric disorders}

It is difficult to discern whether the high prevalence of psychiatric disorders diagnosed during the past SARS-CoV-1 epidemic and largely found in patients with SARS-CoV-2 infection are a direct consequence of the central nervous system involvement or are a fallout of the adverse psychological effects of unprecedented social and health measures such as quarantine, self-isolation and disruption of personal and social healthcare and lifestyle [80]. SARS-CoV-2 infection has recently been implicated in the onset of psychosis, mood disorders, post-traumatic stress disorders and suicide [81-83].

Previous literature on post-traumatic stress disorders reported that more than $40 \%$ of SARS survivors had experienced post-traumatic stress symptoms at one time during the outbreak. Meanwhile, those respondents who had been isolated worked in high-risk workplaces such as SARS wards or had friends or close relatives who contacted SARS were two to three times more likely to develop high levels of posttraumatic stress symptoms than those who were not exposed to the virus. [84]. Recent findings based on the actual outbreak indicate that feeling extreme fear is the most significant predictor for both depression and post-traumatic stress disorder, followed by short sleep duration and living in the worst-hit areas [85].

During and following the COVID-19 outbreak, we might see an increase in suicide ideation and behaviour among atrisk populations. According to the $\mathrm{WHO}$, each suicide in a population is accompanied by more than 20 suicide attempts and a recent model based on global public data from 63 countries predicted a $20-30 \%$ increase of suicide rates due to the COVID-19 pandemic [86, 87].

Besides the social strain, however, it is well known that viral infections may be associated with psychiatric symptoms as a direct neurotropic effect, or (most often) due to activation of a powerful immune-inflammatory response [8]. There is a link between mood disorders and inflammatory cytokine levels, including tumour necrosis factor-alpha (TNF alpha), interleukins (IL-1, IL-6) and others. According to this theory, the proinflammatory cytokines responsible for the acute phase response act on the brain to induce depression. One key player 
in this action of cytokines in the brain is an enzyme known as indoleamine 2,3 dioxygenase (IDO) that degrades tryptophan, an essential amino acid that is the limiting factor for the synthesis of serotonin. An elevation in IDO activity is associated with alterations in brain serotonin neurotransmission and with the development of depressive-like behaviour [76].

Patients with mental health disorders may be particularly vulnerable in the context of the COVID-19 pandemic, not only for their intrinsic psychiatric condition but also because of some of the long-term effects of psychotropic medication (such as metabolic syndrome with long-term antipsychotics), comorbid physical health problems and smoking habits [7]. Furthermore, psychiatric treatment in COVID-19 patients is a source of medical concern. Indeed, from one side, many psychiatric patients have been infected with COVID-19, and on the other side, a contingent number of patients hospitalized for COVID-19 or simply infected by SARS-CoV-2 are experiencing psychiatric symptoms like anxiety, fear, depression and insomnia, which can be difficult to discern from antiviral treatment side effects. In this regard, many patients will need psychiatric medications including antipsychotics, antidepressants and antianxiety drugs, while using specific drugs against COVID-19, such as antiviral or anti-inflammatory. Consistently, the arising question is which drug to use to have the least possible interactions. The best choice seems to be on drugs that do not act on the cytochrome P450 or on drugs that act little on the cytochrome P450, such as citalopram, escitalopram, olanzapine and valproate, to avoid interactions with antivirals, which are metabolized via cytochrome P3A4 and cytochrome P2D6.

Other complications derived from long-lasting in ICU, like impaired consciousness ranging from somnolence to confusion, delirium, stupor and coma, have been reported in almost $15 \%$ of hospitalized patients with COVID-19 [88]. Acute brain dysfunction, symptomatically presenting as delirium (also called encephalopathy), can be a feature of the neuro-invasive potential of SARS-CoV-2. The neurotropism of Coronaviridae has already been demonstrated during the SARS and MERS epidemics. In patients with COVID-19, delirium may be a manifestation of direct central nervous system (CNS) invasion, induction of CNS inflammatory mediators, a secondary effect of other organ system failure, an effect of sedative strategies, prolonged mechanical ventilation or environmental factors including social isolation. Regarding pharmacological interventions, no drugs can be recommended for the prevention or treatment of ICU delirium other than avoidance of overuse of potent psychoactive agents like sedatives and neuromuscular blockers (NMB), unless patients require such management [86].

Therefore, these conditions must be identified and treated early to prevent prolonged mechanical ventilation, longer ICU and hospital length of stay, higher mortality and long-term cognitive impairment.

\section{Conclusions}

The coronavirus disease of 2019 (COVID-19) that is caused by infection with the severe acute respiratory syndrome coronavirus 2 (SARS-CoV-2) has recently been designated a pandemic by the World Health Organization, affecting 4.4 million individuals globally as of May 16, 2020, with over 301.059 deaths. A growing body of evidence supports CNS involvement. The clinical manifestations range from vague non-focal complaints to severe neurologic impairment associated with encephalitis. It is unclear whether neurological dysfunction is due to direct viral injury or systemic disease. The virus may affect brainstem pathways that lead to indirect respiratory dysfunction in addition to direct pulmonary injury. Necessary adaptations in management, triage and diagnosis are needed, especially for subjects suffering from chronic and disabling illness. Finally, precise and targeted documentation of neurological symptoms, detailed clinical, neurological and electrophysiological investigations of the patients, attempts to isolate SARS-CoV-2 from cerebrospinal fluid, and autopsies of the COVID-19 victims may clarify the role played by this virus in causing neurological manifestations.

Acknowledgements PS developed this work within the framework of the DINOGMI, Department of Excellence of MIUR 2018-2022 (Legge 232 del 2016).

Authors' contributions Prof Striano conceptualized, coordinated, supervised data collection and critically reviewed the manuscript for important intellectual content.

Dr. Orsini, Dr. Foiadelli and Drs Corsi designed the study, collected data and drafted, reviewed and revised the manuscript.

Drs Antonella Riva and Dr. Santangelo collected data and drafted, reviewed and revised the manuscript.

Prof Peroni and Prof Savasta critically reviewed the manuscript for important intellectual content.

All authors approved the final manuscript as submitted and agree to be accountable for all aspects of the work.

Data availability Data sharing not applicable to this article as no datasets were generated or analysed during the current study.

\section{Compliance with ethical standards}

Conflict of interest PS has served on a scientific advisory board for the Italian Medicines Agency (AIFA), has received honoraria from GW pharma, Kolfarma s.r.l. and Eisai Inc. and has received research support from the Italian Ministry of Health and Fondazione San Paolo. All the other authors do not report a conflict of interest.

Ethical approval None.

Code availability Not applicable. 


\section{References}

1. Zhu N, Zhang D, Wang W, Li X, Yang B, Song J, Zhao X, Huang B, Shi W, Lu R, Niu P, Zhan F, Ma X, Wang D, Xu W, Wu G, Gao GF, Tan W, China Novel Coronavirus Investigating and Research Team (2020) A novel coronavirus from patients with pneumonia in China, 2019. N Engl J Med 382(8):727-733

2. Zhou P, Yang XL, Wang XG, Hu B, Zhang L, Zhang W, Si HR, Zhu Y, Li B, Huang CL, Chen HD, Chen J, Luo Y, Guo H, Jiang RD, Liu MQ, Chen Y, Shen XR, Wang X, Zheng XS, Zhao K, Chen QJ, Deng F, Liu LL, Yan B, Zhan FX, Wang YY, Xiao GF, Shi ZL (2020) A pneumonia outbreak associated with a new coronavirus of probable bat origin. Nature. 579(7798):270-273

3. WHO. Statement on the second meeting of the International Health Regulations (2005) Emergency Committee regarding the outbreak of novel coronavirus (2019-nCoV) 2020. Available from: https:// www.who.int/news-room/detail/30-01-2020-statement-on-thesecond-meeting-of-the-international-health-regulations-(2005)emergency-committee-regarding-the-outbreak-of-novelcoronavirus-(2019-ncov). Accessed 7 June 2020

4. WHO: Coronavirus disease (COVID-19) Situation Report 138. June 6, 2020

5. Dong Y, Mo X, Hu Y, Qi X, Jiang F, Jiang Z, Tong S (2020) Epidemiology of COVID-19 among children in China. Pediatrics 145:e20200702

6. Li J, Long X, Zhang Q, et al. (2020) Emerging evidence for neuropsycho-consequences of COVID-19. Curr Neuropharmacol. https://doi.org/10.2174/1570159X18666200507085335

7. Smith K, Ostinelli E, Cipriani A (2020) Covid-19 and mental health: a transformational opportunity to apply an evidence-based approach to clinical practice and research. Evid Based Ment Health 23. England:45-46. https://doi.org/10.1136/ebmental-2020300155

8. Holmes EA, O'Connor RC, Perry VH, Tracey I, Wessely S, Arseneault L, Ballard C, Christensen H, Cohen Silver R, Everall I, Ford T, John A, Kabir T, King K, Madan I, Michie S, Przybylski AK, Shafran R, Sweeney A, Worthman CM, Yardley L, Cowan K, Cope C, Hotopf M, Bullmore E (2020) Multidisciplinary research priorities for the COVID-19 pandemic: a call for action for mental health science. Lancet Psychiatry 7:547-560

9. Panda PK, Sharawat IK (2020) COVID-19 (SARS-CoV-2 infection) and children: pediatric neurologist's perspective. Indian $\mathrm{J}$ Pediatr 87(7):556-557. https://doi.org/10.1007/s12098-02003326-8

10. Lu X, Zhang L, Du H, Zhang J, Li YY, Qu J et al (2020) SARSCoV-2 infection in children. N Engl J Med 382(17):1663-1665

11. Li YC, Bai WZ, Hashikawa T (2020) The neuroinvasive potential of SARS-CoV2 may play a role in the respiratory failure of COVID-19 patients. J Med Virol 92(6):552-555. https://doi.org/ 10.1002/jmv. 25728

12. Chen N, Zhou M, Dong X, Qu J, Gong F, Han Y, Qiu Y, Wang J, Liu Y, Wei Y, Xia J', Yu T, Zhang X, Zhang L (2020) Epidemiological and clinical characteristics of 99 cases of 2019 novel coronavirus pneumonia in Wuhan, China: a descriptive study. Lancet. 395(10223):507-513

13. To KF, Lo AW (2004) Exploring the pathogenesis of severe acute respiratory syndrome (SARS): the tissue distribution of the coronavirus (SARS-CoV) and its putative receptor, angiotensinconverting enzyme 2 (ACE2). J Pathol 203(3):740-743

14. Dubé M, Le Coupanec A, Wong AHM, Rini JM, Desforges M, Talbot PJ (2018) Axonal transport enables neuron-to-neuron propagation of human coronavirus OC43. J Virol 92(17):e00404-18. https://doi.org/10.1128/JVI.00404-18

15. Netland J, Meyerholz DK, Moore S, Cassell M, Perlman S (2008) Severe acute respiratory syndrome coronavirus infection causes neuronal death in the absence of encephalitis in mice transgenic for human ACE2. J Virol 82(15):7264-7275

16. Andries K, Pensaert MB (1980) Immunofluorescence studies on the pathogenesis of hemagglutinating encephalomyelitis virus infection in pigs after oronasal inoculation. Am J Vet Res 41(9):1372-1378

17. Baig AM, Khaleeq A, Ali U, Syeda H (2020) Evidence of the COVID-19 virus targeting the CNS: tissue distribution, host-virus interaction, and proposed neurotropic mechanisms. ACS Chem Neurosci 11(7):995-998

18. Wu Y, Xu X, Chen Z, et al (2020) Nervous system involvement after infection with COVID-19 and other coronaviruses. Brain Behav Immun 87:18-22. https://doi.org/10.1016/j.bbi.2020.03.031

19. Li YC, Bai WZ, Hashikawa T (2020) Response to commentary on "The neuroinvasive potential of SARS-CoV-2 may play a role in the respiratory failure of COVID-19 patients". J Med Virol 92(7): 707-709. https://doi.org/10.1002/jmv.25824

20. Yin R, Feng W, Wang T, et al (2020) Concomitant neurological symptoms observed in a patient diagnosed with coronavirus disease 2019. J Med Virol. https://doi.org/10.1002/jmv.25888

21. Huang C, Wang Y, Li X, Ren L, Zhao J, Hu Y, Zhang L, Fan G, Xu J, Gu X, Cheng Z, Yu T, Xia J, Wei Y, Wu W, Xie X, Yin W, Li H, Liu M, Xiao Y, Gao H, Guo L, Xie J, Wang G, Jiang R, Gao Z, Jin Q, Wang J, Cao B (2020) Clinical features of patients infected with 2019 novel coronavirus in Wuhan, China. Lancet 395(10223):497506

22. Mao L, Jin H, Wang M, et al (2020) Neurologic manifestations of hospitalized patients with coronavirus disease 2019 in Wuhan, China. JAMA Neurol 77(6):1-9. https://doi.org/10.1001/ jamaneurol.2020.1127

23. Mehta P, McAuley DF, Brown M, Sanchez E, Tattersall RS, Manson JJ (2020) COVID-19: consider cytokine storm syndromes and immunosuppression. Lancet 395(10229):1033-1034

24. Bohmwald K, Galvez NMS, Rios M, Kalergis AM (2018) Neurologic alterations due to respiratory virus infections. Front Cell Neurosci 12:386

25. Asadi-Pooya AA, Simani L (2020) Central nervous system manifestations of COVID-19: a systematic review. J Neurol Sci 413: 116832

26. Lechien JR, Chiesa-Estomba CM, De Siati DR, et al (2020) Olfactory and gustatory dysfunctions as a clinical presentation of mild-to-moderate forms of the coronavirus disease (COVID-19): a multicenter European study. Eur Arch Otorhinolaryngol 277(8): 2251-2261. https://doi.org/10.1007/s00405-020-05965-1

27. Giacomelli A, Pezzati L, Conti F, et al (2020) Self-reported olfactory and taste disorders in SARS-CoV-2 patients: a cross-sectional study. Clin Infect Dis. https://doi.org/10.1093/cid/ciaa330

28. Xiang P, Xu XM, Gao LL, Wang HZ, Xiong HF, Li RH (2020) First case of 2019 novel coronavirus disease with encephalitis. ChinaXiv 202003:00015

29. Moriguchi T, Harii N, Goto J, Harada D, Sugawara H, Takamino J, Ueno M, Sakata H, Kondo K, Myose N, Nakao A, Takeda M, Haro H, Inoue O, Suzuki-Inoue K, Kubokawa K, Ogihara S, Sasaki T, Kinouchi H, Kojin H, Ito M, Onishi H, Shimizu T, Sasaki Y, Enomoto N, Ishihara H, Furuya S, Yamamoto T, Shimada S (2020) A first case of meningitis/encephalitis associated with SARS-coronavirus-2. Int J Infect Dis 94:55-58

30. Poyiadji N, Shahin G, Noujaim D, Stone M, Patel S, Griffith B (2020) COVID-19-associated acute hemorrhagic necrotizing encephalopathy: CT and MRI features. Radiology 201187. https:// doi.org/10.1148/radiol.2020201187

31. Wu X, Wu W, Pan W, Wu L, Liu K, Zhang HL (2015) Acute necrotizing encephalopathy: an underrecognized clinicoradiologic disorder. Mediat Inflamm 2015:792578

32. Wang H, Ma S (2008) The cytokine storm and factors determining the sequence and severity of organ dysfunction in multiple organ dysfunction syndrome. Am J Emerg Med 26(6):711-715 
33. Avula A, Nalleballe K, Narula N, Sapozhnikov S, Dandu V, Toom S, Glaser A, Elsayegh D (2020) COVID-19 presenting as stroke. Brain Behav Immun 87:115-119

34. Oxley TJ, Mocco J, Majidi S, Kellner CP, Shoirah H, Singh IP et alLarge-vessel stroke as a presenting feature of Covid-19 in the young. N Engl J Med 3822020:e60

35. Klok FA, Kruip M, van der Meer NJM, Arbous MS, Gommers D, Kant KM et al (2020) Incidence of thrombotic complications in critically ill ICU patients with COVID-19. Thromb Res 191:145147

36. Lippi G, Plebani M, Henry BM (2020) Thrombocytopenia is associated with severe coronavirus disease 2019 (COVID-19) infections: a meta-analysis. Clin Chim Acta 506:145-148

37. Iadecola C, Anrather J (2011) The immunology of stroke: from mechanisms to translation. Nat Med 17(7):796-808

38. Doobay MF, Talman LS, Obr TD, Tian X, Davisson RL, Lazartigues E (2007) Differential expression of neuronal ACE2 in transgenic mice with overexpression of the brain reninangiotensin system. Am J Physiol Regul Integr Comp Physiol 292(1):R373-R381

39. Zhao H, Shen D, Zhou H, Liu J, Chen S (2020) Guillain-Barre syndrome associated with SARS-CoV-2 infection: causality or coincidence? Lancet Neurol 19(5):383-384

40. Toscano G, Palmerini F, Ravaglia S, et al (2020) Guillain-Barré syndrome associated with SARS-CoV-2. N Engl J Med 382(26): 2574-2576. https://doi.org/10.1056/NEJMc2009191

41. Assini A, Benedetti L, Di Maio S, Schirinzi E, Del Sette M (2020) New clinical manifestation of COVID-19 related Guillain-Barrè syndrome highly responsive to intravenous immunoglobulins: two Italian cases. Neurol Sci. https://doi.org/10.1007/s10072-02004484-5

42. Oguz-Akarsu E, Ozpar R, Mirzayev H, et al (2020) Guillain-Barré syndrome in a patient with minimal symptoms of COVID-19 infection. Muscle Nerve. https://doi.org/10.1002/mus.26992

43. Camdessanche JP, Morel J, Pozzetto B, Paul S, Tholance Y, Botelho-Nevers E (2020) COVID-19 may induce Guillain-Barré syndrome. Rev Neurol (Paris) 176(6):516-518

44. Multiple Sclerosis International Federation. Global COVID-19 advice for people with MS https://www.msif.org/. Accessed 7 June 2020

45. Brownlee W, Bourdette D, Broadley S, Killestein J, Ciccarelli O (2020) Treating multiple sclerosis and neuromyelitis optica spectrum disorder during the COVID-19 pandemic. Neurology. 94: 949-952

46. Amor S, Baker D, Khoury SJ, Schmierer K, Giovanonni G (2020) SARS-CoV-2 and multiple sclerosis: not all immune depleting DMTs are equal or bad. Ann Neurol n/a(n/a)

47. Winkelmann A, Loebermann M, Reisinger EC, Hartung HP, Zettl UK (2016) Disease-modifying therapies and infectious risks in multiple sclerosis. Nat Rev Neurol 12(4):217-233

48. Guidon AC, Amato AA (2020) COVID-19 and neuromuscular disorders. Neurology 94:959-969

49. Gummi RR, Kukulka NA, Deroche CB, Govindarajan R (2019) Factors associated with acute exacerbations of myasthenia gravis. Muscle Nerve 60(6):693-699

50. Szperka CL, Ailani J, Barmherzig R, Klein BC, Minen MT, Halker Singh RB, Shapiro RE (2020) Migraine care in the era of COVID19: clinical pearls and plea to insurers. Headache. 60(5):833-842

51. EMA gives advice on the use of non-steroidal anti-inflammatories for COVID-19

52. Muller KI, Alstadhaug KB, Bekkelund SI (2017) A randomized trial of telemedicine efficacy and safety for nonacute headaches. Neurology. 89(2):153-162

53. Qubty W, Patniyot I, Gelfand A (2018) Telemedicine in a pediatric headache clinic: a prospective survey. Neurology 90(19):e1702e17e5
54. Bove R, Bevan C, Crabtree E, Zhao C, Gomez R, Garcha P, Morrissey J, Dierkhising J, Green AJ, Hauser SL, Cree BAC, Wallin MT, Gelfand JM (2019) Toward a low-cost, in-home, telemedicine-enabled assessment of disability in multiple sclerosis. Mult Scler 25(11):1526-1534

55. Carlotti APdCP, Carvalho WBd, Johnston C, Rodriguez IS, Delgado AF (2020) COVID-19 diagnostic and management protocol for pediatric patients. Clinics 75

56. Cortegiani A, Ingoglia G, Ippolito M, Giarratano A, Einav S (2020) A systematic review on the efficacy and safety of chloroquine for the treatment of COVID-19. J Crit Care 57:279-283

57. Gautret P, Lagier JC, Parola P, et al (2020) Hydroxychloroquine and azithromycin as a treatment of COVID-19: results of an open-label non-randomized clinical trial. Int J Antimicrob Agents 105949. https://doi.org/10.1016/j.ijantimicag.2020.105949

58. Sun J, Chen Y, Fan X, Wang X, Han Q, Liu Z (2020) Advances in the use of chloroquine and hydroxychloroquine for the treatment of COVID-19. Postgrad Med:1-10. https://doi.org/10.1080/ 00325481.2020 .1778982

59. Chen J, Liu D, Liu L, Liu P, Xu Q, Xia L, Ling Y, Huang D, Song S, Zhang D, Qian Z, Li T, Shen Y, Lu H (2020) A pilot study of hydroxychloroquine in treatment of patients with moderate COVID-19. Zhejiang Da Xue Xue Bao Yi Xue Ban 49(2):215-219

60. Alhazzani W, Møller MH, Arabi YM, Loeb M, Gong MN, Fan E, Oczkowski S, Levy MM, Derde L, Dzierba A, du B, Aboodi M, Wunsch H, Cecconi M, Koh Y, Chertow DS, Maitland K, Alshamsi F, Belley-Cote E, Greco M, Laundy M, Morgan JS, Kesecioglu J, McGeer A, Mermel L, Mammen MJ, Alexander PE, Arrington A, Centofanti JE, Citerio G, Baw B, Memish ZA, Hammond N, Hayden FG, Evans L, Rhodes A (2020) Surviving Sepsis Campaign: guidelines on the management of critically ill adults with Coronavirus Disease 2019 (COVID-19). Intensive Care Med 46(5):854-887

61. Agenzia Italiana del Farmaco (AIFA): AIFA sospende l'autorizzazione all'utilizzo di idrossiclorochina per il trattamento del COVID-19 al di fuori degli studi clinici

62. Mulhauser P, Allemann Y, Regamey C (1995) Chloroquine and nonconvulsive status epilepticus. Ann Intern Med 123(1):76-77

63. Wang M, Cao R, Zhang L, Yang X, Liu J, Xu M et al (2020) Remdesivir and chloroquine effectively inhibit the recently emerged novel coronavirus (2019-nCoV) in vitro. Cell Res 30. England:269-271

64. Holshue ML, DeBolt C, Lindquist S, Lofy KH, Wiesman J, Bruce H, Spitters C, Ericson K, Wilkerson S, Tural A, Diaz G, Cohn A, Fox L, Patel A, Gerber SI, Kim L, Tong S, Lu X, Lindstrom S, Pallansch MA, Weldon WC, Biggs HM, Uyeki TM, Pillai SK, Washington State 2019-nCoV Case Investigation Team (2020) First case of 2019 novel coronavirus in the United States. N Engl J Med 382(10):929-936

65. Russo EILClinically relevant drug-drug interaction between AEDs and medications used in the treatment of COVID-19 patients. Italian League Against Epilepsy

66. Jean SS, Lee PI, Hsueh PR (2020) Treatment options for COVID19: the reality and challenges. J Microbiol Immunol Infect 53(3): 436-443. https://doi.org/10.1016/j.jmii.2020.03.034

67. Cao B, Wang Y, Wen D, Liu W, Wang J, Fan G, Ruan L, Song B, Cai Y, Wei M, Li X, Xia J, Chen N, Xiang J, Yu T, Bai T, Xie X, Zhang L, Li C, Yuan Y, Chen H, Li H, Huang H, Tu S, Gong F, Liu Y, Wei Y, Dong C, Zhou F, Gu X, Xu J, Liu Z, Zhang Y, Li H, Shang L, Wang K, Li K, Zhou X, Dong X, Qu Z, Lu S, Hu X, Ruan S, Luo S, Wu J, Peng L, Cheng F, Pan L, Zou J, Jia C, Wang J, Liu X, Wang S, Wu X, Ge Q, He J, Zhan H, Qiu F, Guo L, Huang C, Jaki T, Hayden FG, Horby PW, Zhang D, Wang C (2020) A trial of lopinavir-ritonavir in adults hospitalized with severe Covid-19. N Engl J Med 382(19):1787-1799 
68. Brooks J, Daily J, Schwamm L (1997) Protease inhibitors and anticonvulsants. AIDS Clin Care 9(11):87-90

69. May EF, Calvert PC (1990) Aggravation of myasthenia gravis by erythromycin. Ann Neurol 28(4):577-579

70. AIFA. Sperimentazioni cliniche - COVID-19 [updated March 27, 2020. Available from: https://www.aifa.gov.it/-/covid-19aggiornamento-studi-clinici-autorizzati. Accessed 7 June 2020

71. CDC COVID-19 Response Team (2020) Coronavirus Disease 2019 in Children - United States, February 12-April 2, 2020. MMWR Morb Mortal Wkly Rep 69(14):422-426. https://doi.org/ 10.15585/mmwr.mm6914e4

72. WHO. Report of the WHO-China Joint Mission on Coronavirus Disease 2019 (COVID-19)

73. Task force COVID-19 del Dipartimento Malattie Infettive e Servizio di Informatica, Istituto Superiore di Sanità. Epidemia COVID-19, Aggiornamento nazionale: 23 aprile 2020

74. Cai J, Xu J, Lin D, et al (2020) A case series of children with 2019 novel coronavirus infection: clinical and epidemiological features. Clin Infect Dis. https://doi.org/10.1093/cid/ciaa198

75. Xu Y, Li X, Zhu B, Liang H, Fang C, Gong Y, Guo Q, Sun X, Zhao D, Shen J, Zhang H, Liu H, Xia H, Tang J, Zhang K, Gong S (2020) Characteristics of pediatric SARS-CoV-2 infection and potential evidence for persistent fecal viral shedding. Nat Med 26(4):502505

76. Henry BM, Lippi G, Plebani M (2020) Laboratory abnormalities in children with novel coronavirus disease 2019. Clin Chem Lab Med 58(7):1135-1138. https://doi.org/10.1515/cclm-2020-0272

77. Sun D, Li H, Lu XX, Xiao H, Ren J, Zhang FR, Liu ZS (2020) Clinical features of severe pediatric patients with coronavirus disease 2019 in Wuhan: a single center's observational study. World J Pediatr 16:251-259

78. Tan X, Huang J, Zhao F, Zhou Y, Li JQ, Wang XY (2020) Clinical features of children with SARS-CoV-2 infection: an analysis of 13 cases from Changsha, China. Zhongguo Dang Dai Er Ke Za Zhi 22(4):294-298

79. Streng A, Hartmann K, Armann J, Berner R, Liese JG (2020) COVID-19 bei hospitalisierten Kindern und Jugendlichen: Ein systematischer Review zu publizierten Fallserien (Stand 31.03.2020) und erste Daten aus Deutschland. [COVID-19 in hospitalized children and adolescents]. Monatsschr Kinderheilkd 1-12. https://doi.org/10.1007/s00112-020-00919-7

80. Galea S, Merchant RM, Lurie N (2020) The mental health consequences of COVID-19 and physical distancing: the need for prevention and early intervention. JAMA Intern Med 180:817
81. Gunnell D, Appleby L, Arensman E, Hawton K, John A, Kapur N, Khan M, O'Connor RC, Pirkis J, Appleby L, Arensman E, Caine ED, Chan LF, Chang SS, Chen YY, Christensen H, Dandona R, Eddleston M, Erlangsen A, Gunnell D, Harkavy-Friedman J, Hawton K, John A, Kapur N, Khan M, Kirtley OJ, Knipe D, Konradsen F, Liu S, McManus S, Mehlum L, Miller M, Moran P, Morrissey J, Moutier C, Niederkrotenthaler T, Nordentoft M, O’Connor RC, O’Neill S, Page A, Phillips MR, Pirkis J, Platt S, Pompili M, Qin P, Rezaeian M, Silverman M, Sinyor M, Stack S, Townsend E, Turecki G, Vijayakumar L, Yip PSF (2020) Suicide risk and prevention during the COVID-19 pandemic. Lancet Psychiatry 7:468-471

82. Severance EG, Dickerson FB, Viscidi RP, Bossis I, Stallings CR, Origoni AE, Sullens A, Yolken RH (2009) Coronavirus immunoreactivity in individuals with a recent onset of psychotic symptoms. Schizophr Bull 37(1):101-107

83. Okusaga O, Yolken RH, Langenberg P, Lapidus M, Arling TA, Dickerson FB, Scrandis DA, Severance E, Cabassa JA, Balis T, Postolache TT (2011) Association of seropositivity for influenza and coronaviruses with history of mood disorders and suicide attempts. J Affect Disord 130(1-2):220-225

84. Liu N, Zhang F, Wei C, Jia Y, Shang Z, Sun L, Wu L, Sun Z, Zhou Y, Wang Y, Liu W (2020) Prevalence and predictors of PTSS during COVID-19 outbreak in China hardest-hit areas: gender differences matter. Psychiatry Res 287:112921

85. Tang W, Hu T, Hu B, Jin C, Wang G, Xie C, Chen S, Xu J (2020) Prevalence and correlates of PTSD and depressive symptoms one month after the outbreak of the COVID-19 epidemic in a sample of home-quarantined Chinese university students. J Affect Disord 274:1-7

86. Klomek AB (2020) Suicide prevention during the COVID-19 outbreak. Lancet Psychiatry 7(5):390

87. Kawohl W, Nordt C (2020) COVID-19, unemployment, and suicide. Lancet Psychiatry 7(5):389-390

88. Zambrelli E, Canevini M, Gambini O, D'Agostino A (2020) Delirium and sleep disturbances in COVID-19: a possible role for melatonin in hospitalized patients? Sleep Med 70:111

Publisher's note Springer Nature remains neutral with regard to jurisdictional claims in published maps and institutional affiliations. 